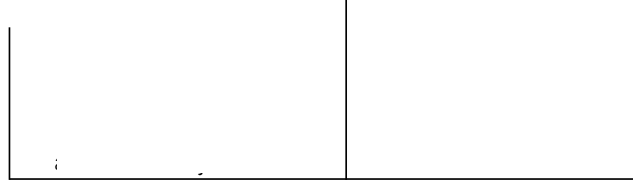

Rev. Latinoam. Psicopat. Fund., V, 2, 166-167

Más allá de la persona: hacia una psicoterapia fenomenológica mundana Virginia Moreira

Santiago: Ed. Universidad de Santiago de Chile

\title{
Más allá de la persona: hacia una psicoterapia fenomenológica mundana*
}

\section{Tod Sloan}

¿Qué es la persona? ¿Qué está pasando cuando una persona tiene dificultades y problemas en su vida? ¿Qué significa la depresión o la ansiedad que experimenta la persona con problemas?

Hace cincuenta años, varios psicólogos norteamericanos ofrecieron sus respuestas a estas preguntas y, como surgían dentro de la industria nueva de la psicología clínica, con recursos amplios y durante una época de creciente individualismo consumista, despúes de una depresión económica y una guerra mundial, que habían producido una cultura de conformismo autoritario, sus respuestas fueron aceptadas por muchos psicólogos que se formaron en los años 1960 y 1970, y todavía. Así nació la psicologia humanista, un enfoque que se alejaba del reduccionismo del conductismo y del psicoanalisis. Entre los teóricos clínicos que levantaron su voz para establecer esta tercera ola en la psicología norteamericana, el más importante fue Carl Rogers.

Para responder a las necesidades de personas con problemas emocionales, Rogers propuso una terapia centrada en la persona, en base a una imagen de la persona como un organismo que es capaz de crecer naturalmente si sólo siente la aceptación de la gente en su entorno. La

* Comunicação proferida por ocasião da cerimônia de lançamento do livro, realizada na Universidade de Fortaleza em 27 de setembro de 2001. 
cultura autoritaria y conformista había producido muchas personas que se sentían congeladas, juzgadas, bloqueadas de diversas maneras, por lo tanto, tenían que ser liberadas.

Rogers y sus colegas propusieron un tratamiento de aceptación, de amor incondicional, para promover un nuevo crecimiento personal en estos casos, una auto-realización que se desenvolvería naturalmente al dar las condiciones necesarias. El psicólogo solo tenía que escuchar y reflejar los sentimientos expresados por sus clientes para facilitar este proceso. Ninguna interpretación del inconsciente, ningún consejo directivo. Solo tenía que comunicar aceptación.

Ahora bien, dentro de aquella sociedad caracterizada por la competencia, la desigualdad, y el conformismo, un poco de aceptación fué capaz de producir milagros. De hecho, la terapia centrada en la persona no es inferior a otros enfoques en sus resultados.

El problema queda en otra parte y es el gran aporte del libro de la Dra. Virginia Moreira, de habernos señalado los serios límites de esta visión humanista de la persona. Ella nos senála que es más allá de la persona, es todo el mundo que constituye una persona, todo lo que hace parte del individuo, lo que da sentido a su existencia. El individualismo de Rogers y otros psicólogos humanistas habían sacado a la persona de su mundo social, histórico, cultural y natural, dejándolo solo, sin acceso a los recursos que proveen estos mundos.

El esfuerzo de la Dra. Moreira es proponer una terapia mundana, que reconoce que la salud mental depende de la posibilidad de abrirse al mundo social, al movimiento del tiempo y de la história, a las sensaciones del cuerpo, a las percepciones y perspectivas múltiples que nos ofrece la existencia. Ella reconoce que muchos sufrimos de la "neurosis contemporánea", que es una manera rígida de organizar nuestra relación personal con el mundo. Lo define así: “... el paciente nunca tiene tiempo, es cada vez menos capaz de expresar sentimientos, sufre por su rigidez, es esclavo del trabajo, del estatus, del consumismo, de la tecnología y de la soledad que acompaña la globalización. Quiere vivir en un mundo exacto, concreto, donde se siente seguro" (p. 303).

La terapia mundana intentaría, en base a la fenomenología de Merleau-Ponty, el filósofo francés, reabrir la dialéctica individuo-mundo, la relación dinámica entre lo real y lo imaginario, y el movimiento de construcción de la existencia cotidiana.

Carl Rogers nos prometió la auto-realización, pero él no entrega el camino porque su individualismo lo deja ciego. Virginia Moreira no nos hace promesas, pero indica caminos múltiples que podemos explorar si queremos vivir plenamente más allá de la persona, con el mundo y en el mundo.

Espero que no tengamos que esperar mucho tiempo para leer su próximo libro! 